\title{
Teatralidad en proceso: la obra de Roberto Arlt
}

\author{
Laura Sáez Reta ${ }^{1}$
}

Resumen. El paso de la novela al teatro de Roberto Arlt siempre ha interesado a la crítica literaria. Este trabajo detalla el camino que recorrió el autor en la transición de un género a otro y repasa las principales teorías que intentan explicar los motivos de este cambio, para hablar, después, de la presencia de la teatralidad en toda su obra; de las conexiones de su narrativa con la tradición teatral argentina; del origen de su dramaturgia en relación al proyecto del Teatro del Pueblo; y, por último, de la narratividad de sus últimas obras.

Palabras clave: teatralidad; tradición teatral; teatro independiente; novela; narratividad.

\section{[en] Theatricality in process: Roberto Arlt's work}

Abstract. Roberto Arlt's transition from novel to theater has always interested literary studies. This article details the path taken by the author in the shift from one genre to another and reviews the main theories which attempt to explain the reasons for this change. Then, we will talk about the presence of theatricality (or better showmanship) in all of his work; the connections of his narrative with the Argentine theater tradition; the origin of his dramaturgy in relation to the Teatro del Pueblo project; and, finally, the narrativity of his last works.

Keywords: theatricality/showmanship; theatrical tradition; independent theater; novel; narrativity.

Sumario. 1. ...y no volvió a escribir novelas. 2. La teatralidad en la obra de Arlt. 3. Narrativa y tradición teatral, dramaturgia y teatro independiente. 4. El otro giro.

Cómo citar: Sáez Reta, L. (2021) Teatralidad en proceso: la obra de Roberto Arlt, en Anales de Literatua Hispanoamericana 50, 319-327.

\section{1. ... y no volvió a escribir novelas}

A primera vista, y dejando de lado (de momento) los cuentos y las aguafuertes, la trayectoria literaria de Roberto Arlt se divide clara y cronológicamente en dos grandes ciclos, el de novelista y el de dramaturgo. 1932 se suele señalar como el momento de transición entre uno y otro: en un mismo año, Arlt publica la que será su última novela, El amor brujo (que aparece en abril en la editorial Victoria), y estrena su primera pieza teatral consagrada, Trescientos millones, en el Teatro del Pueblo (el 17 de junio ${ }^{2}$ ). Hasta entonces había publicado un ensayo de ficción, Las ciencias ocultas en la ciudad de Buenos Aires (Tribuna Libre, $\mathrm{n}^{\mathrm{o}}$. 63, 28 de enero de 1920), y tres novelas más, El juguete rabioso (Buenos Aires, Latina, 1926) y la saga de Los siete locos (Buenos Aires, Latina, 1929) y Los lanzallamas (Buenos Aires, Claridad, 1931). Además, había anunciado en su columna diaria de El Mundo la segunda parte de El amor brujo, El pájaro de fuego, de la que había bosquejado el argumento y adelantado algunos fragmentos pero que nunca llegó a escribir.

La crítica escoge 1932 como punto de inflexión por coincidir en ese año el fin de un ciclo y el principio de otro, pero la dedicación de Arlt al teatro es un proceso complejo, en el que se solapan diversas circunstancias. A mediados de 1931, Leónidas Barletta (que había fundado el Teatro del Pueblo en

\footnotetext{
${ }^{1}$ Universidad Autónoma de Madrid. España.

E-mail: laura.saezr@estudiante.uam.es

2 Dependiendo de las fuentes consultadas, las fechas de los estrenos de algunas piezas de Arlt varían en días, meses e incluso años (el caso más llamativo es el de La isla desierta, que se sitúa indistintamente en 1937 o 1938). Tras contrastar distintas referencias, en este trabajo voy a usar aquellas que parecen de acuerdo mayoritario, recogidas en Sanz (2000), salvo excepciones que se indicarán.
} 
noviembre de 1930 como iniciativa de teatro independiente) reúne a una serie de escritores, Arlt entre ellos, para pedirles su colaboración en el proyecto. El autor adapta, entonces, un fragmento de Los siete locos, "El humillado" 3 , que se estrenará bajo la dirección de Barletta en marzo de $1932^{4}$, y escribe su primer texto teatral, Prueba de amor, subtitulado "boceto irrepresentable ante personas honestas" (Arlt, 1981b: 377), que se estrenó fugazmente ese año y apareció editado por Rañó en septiembre junto a Trescientos millones.

Tras estos primeros acercamientos a las tablas, Arlt empezó a implicarse poco a poco, más y más en el mundo del teatro; pero, si bien es cierto que no volvió a escribir novelas -o, al menos, no como lo había hecho hasta entonces-, su nueva faceta de dramaturgo convivió con el desarrollo siempre constante de su producción cuentística y periodística. Así, mientras participaba en las actividades del Teatro del Pueblo, se ocupó, durante abril y mayo de 1933, de la sección "Vida teatral" de El Mundo (en sus aguafuertes ya había hecho algunos comentarios sobre la situación del teatro argentino de la época y reseñado algunas obras) ${ }^{6}$, y preparó su primera recopilación de cuentos ${ }^{7}$, El jorobadito (Buenos Aires, Anaconda), que se publicó en septiembre de ese mismo año, al igual que sus Aguafuertes porteñas (Buenos Aires, Victoria) ${ }^{8}$.

En 1934 el autor avanza en sus intentos de creación dramática9 : a lo largo del año publica en prensa tres breves bocetos teatrales que no llegaron a representarse, pero que contienen la mayoría de temas y elementos compositivos que caracterizarán su teatro y que se desarrollarán en piezas posteriores. Por ejemplo, en $L a$ juerga de los polichinelas (La Nación, 25 de marzo) se cuestionan, como en muchas obras de Arlt, las instituciones burguesas del noviazgo, el matrimonio y el adulterio, pero de un modo menos dramático que en El amor brujo o Prueba de amor, con un punto de humor por contraste, rozando el absurdo, que se acercará al tono propio de los géneros dramáticos que más practicó: la farsa y la burlería. Además, en esta pieza Arlt juega con la locura como enfermedad mental ${ }^{10}$ - al final se descubre que los personajes del Marido y el Criado se han fugado de un "hospicio de dementes" (Arlt, 1981b: 737) y son perseguidos por sus cuidadores-, recurso que utilizará de nuevo poco después como centro de Escenas de un grotesco (La Gaceta de Buenos Aires, 4 de agosto): el escenario de este siguiente boceto es un manicomio y la acción, la representación de un espectáculo teatral que sus pacientes llevan a cabo ante un grupo de periodistas. Por esta unión de representación y locura, y lo parecido del carácter y el proceso de los personajes principales, este texto se considera el antecedente directo de Saverio el cruel (1936) ${ }^{11}$. Por otro lado, Un hombre sensible (La Nación, 13 de mayo) recuerda a esas aguafuertes en las que se describen y parodian distintos tipos de vagos porteños ${ }^{12}$ —en este caso, el Rentista- e introduce el mundo de las oficinas, donde la juventud y los sueños son destruidos por un empleo mediocre, que encontraremos en La isla desierta (1937/8) y El desierto entra en la ciudad (1942), así como la idea de que el aburrimiento empuja a la gente rica y ociosa a organizar bromas, farsas espectaculares para entretenerse, como ocurrirá con los jóvenes de Saverio el cruel.

Pero Arlt no se afianza como dramaturgo hasta 1936, cuando empieza a escribir obras largas con estructuras más compensadas, si las comparamos con Trescientos millones, su única pieza larga con repercusión hasta esa fecha, cuya acción (con un primer acto muy prolongado en relación a un segundo y un tercero mucho más breves donde se acumulan los acontecimientos) resulta muy desigual. Tras regresar en mayo de ese año de su viaje por España y el norte de África ${ }^{13}$, estrenó Saverio el cruel (26 de agosto) y El

${ }^{3}$ Saítta (2000: 92) apunta que este fragmento ya circulaba de forma independiente en la antología Cuentistas argentinos de hoy (1921-1928) (Buenos Aires, Claridad, 1929).

${ }^{4}$ El día 3 (Saítta, 2000: 93) o el 25 (Verzero, 2006: 11).

${ }^{5}$ Hay pocas referencias a este estreno de 1932, que Ogás (2011: 40) menciona. La representación que tuvo más repercusión y que se suele tomar como primera de este texto es la que tuvo lugar en octubre de 1947 en La Casa del Teatro.

${ }^{6}$ Para un listado de todos los trabajos periodísticos de Arlt sobre el teatro véase Sanz (2000: 170-171).

${ }^{7}$ De la veintena de cuentos que Arlt había publicado entre 1928 y 1932 en las revistas El Hogar y Mundo Argentino, y en los periódicos El Mundo y La Nación, nueve fueron incluidos en este volumen, con algunas variantes (Gnutzmann, 2004: 109).

${ }^{8}$ Desde mediados de 1928, y hasta su muerte en julio de 1942, Arlt trabajó para El Mundo escribiendo notas diarias. En ellas, reflexionaba con su ironía y ternura particulares sobre la ciudad de Buenos Aires y sus problemas, sus habitantes, su lenguaje, sus barrios... Este espacio fue una manera de ganarse la vida, pero también un lugar desde el que hablar, y resultó fundamental para su trayectoria vital y literaria. Esta primera selección reunió un pequeño porcentaje de las mil quinientas que había publicado hasta entonces (Saítta, 2000: 87).

${ }^{9}$ Todavía encontramos, por las mismas fechas, algún testimonio de que seguía trabajando en El pájaro de fuego: una carta a E. J. Arizaga, fechada el 2 de marzo de 1934, en la que Arlt adelanta parte del argumento, y un fragmento de la novela, que apareció en El Mundo una semana después, compuesto por un diálogo entre Balder y el Fantasma. Ambas referencias proceden de Saítta (2000: 87-91).

${ }^{10}$ Hasta ahora, los personajes de Arlt (Astier, Erdosain, Balder...) se habían enfrentado a la locura como duda existencial, como cuestionamiento de su propia conducta, de su personalidad.

${ }^{11}$ Castagnino (1964) habla de esta relación y recupera algunos fragmentos del boceto.

${ }^{12}$ Como "El hombre de la camiseta calada" (Arlt, 1981b: 51-53) o "El siniestro mirón" (80-81).

${ }^{13}$ En febrero de 1935 El Mundo envió a Arlt como cronista a España y el norte de África: en sus notas fue describiendo lo que veía y contando sus peripecias en un clima politizado, prebélico y plagado de espías que, junto al mundo oriental que conoció en Tánger y Tetuán, marcará su 
fabricante de fantasmas ( 8 de octubre) ${ }^{14}$, a las que siguieron La isla desierta (estrenada en algún momento entre septiembre de 1937 y marzo de 1938), Separación feroz (diálogo dramático publicado en el diario El Litoral, de Santa Fe, el 1 enero 1938) ${ }^{15}$, África (17 de marzo de 1938), La fiesta del hierro (18 de julio de 1940) y El desierto entra en la ciudad $(1942)^{16}$. Mientras tanto, continuó con sus notas habituales (la segunda edición de Aguafuertes porteñas apareció en Futuro, en 1950) e incrementó su producción de cuentos $^{17}$, aunque solo recogió en libro los quince de la colección El criador de gorilas (Santiago de Chile, Zig-Zag, 1941), y además publicó la novela corta Viaje terrible (Nuestra Novela, $\mathrm{n}^{\circ}$. 6, 11 de julio de $1941)^{18}$.

El paso de Arlt al teatro ha despertado a menudo la fascinación de la crítica. Lo atractivo de una afirmación tan contundente como "... y no volvió a escribir novelas" ha dado lugar a una serie de trabajos que intentan explicar ese misterioso giro hacia la dramaturgia, agrandando, muchas veces, lo abrupto y definitivo del gesto, y cubriendo de un aura romántica la figura del escritor. Así, por ejemplo, Ogás (2011: 33) resume la cuestión en que, tras la puesta en escena de "El humillado", "Arlt relega la narrativa y se aboca hasta su muerte (1942) a la escritura dramática", pasando por alto los cuentos posteriores a 1932 y lo progresivo de su dedicación al teatro. En otros estudios se habla de este giro hacia la dramaturgia como de una necesidad latente en el autor, una evolución que acabaría produciéndose inevitablemente. Según Goloboff (1989: 87), "un desenvolvimiento interno casi obligado lo alienta, muy probablemente, a encontrar en la escena el marco adecuado para la extraversión y el tratamiento de sus temas fundamentales", y Mirta Arlt (1990) sugiere que:

Arlt no se había enterado de que era un dramaturgo, mejor dicho, que el dramaturgo estaba surgiendo del novelista, como una mutación natural, como la de la serpiente que se come a otra serpiente y se convierte en dragón. Hizo falta que Barletta le mostrara el desplazamiento del texto escrito al escenario [...]. Entonces Arlt supo y entró en la piel del dragón.

En cambio, en otros trabajos que también lo relacionan con la intervención de Barletta y la representación de "El humillado", se considera un cambio casual (Ogás, 2011: 33).

Varios críticos lo atribuyen al espíritu inquieto de Arlt, además de a otros factores: Gatti (2008) opina que, a sus ganas de experimentar después de haber alcanzado el éxito como novelista —lo que descartaría la motivación económica, especialmente si tenemos en cuenta en qué circuitos se movieron sus piezas-, se suma un afán por democratizar la cultura - aunque se discute si finalmente su elección del teatro independiente no acabó siendo elitista-, y Saítta (2000), que, quizás empujado por la escasa acogida de $E l$ amor brujo y una vez implicado en el proyecto del Teatro del Pueblo, su interés por la creación dramática se desarrolló de manera natural.

Por último, encontramos algunas explicaciones más elaboradas y concretas, aunque un tanto rebuscadas: Mavridis (2006: [En línea]) propone que la nota final de Los lanzallamas, en la que Arlt admite con orgullo que las primeras páginas del libro se estaban imprimiendo mientras todavía redactaba las últimas,

revela cierta voluntad del autor de traspasar los límites que separan todo el proceso literario, desde la redacción hasta la difusión y recepción de sus escritos. De esta manera quiso romper con los mediadores de la literatura y revela su rebelión frente a la institución arte. De ahí se explica su dedicación completa al teatro, puesto que es la única modalidad en la cual se dan todos los procedimientos artísticos simultáneamente en un momento de captación de la literatura en su presencia absoluta;

producción literaria posterior. El escritor ya había viajado antes como corresponsal del diario: de marzo a mayo de 1930 realizó una breve gira por Montevideo y Río de Janeiro; en agosto y septiembre de 1933 recorrió el río Paraná y las ciudades del litoral argentino; y en enero de 1934 visitó la zona de Patagones, Viedma y Bariloche. Y volvió a hacerlo una vez más, de noviembre de 1940 a enero de 1941 , en esa ocasión con destino a Chile (Saítta, 2000).

${ }^{14}$ Excepto los esbozos publicados en prensa y El fabricante de fantasmas, que se estrenó en el Teatro Argentino y acabó siendo la única y fracasada experiencia de Arlt en un circuito más comercial (la obra solo duró una semana en cartel), todas sus piezas se estrenaron en el Teatro del Pueblo.

${ }^{15}$ Según Castagnino (1964) no se conocen representaciones de la época.

${ }^{16}$ Última obra de Arlt, acabada pero sin revisar, en 1952 Mirta Arlt (2000) autorizó su publicación en la editorial Futuro y ese mismo año fue estrenada por el grupo de teatro independiente El Duende, en el actual Teatro Regina.

${ }^{17}$ Saítta (2000: 172) señala que "Arlt escribe veintisiete cuentos en diez años (de 1926 a 1936) y escribirá más del doble, sesenta y dos relatos en los seis años restantes (1937 a 1942)".

${ }^{18}$ Este relato tuvo dos versiones anteriores: la primera, “¡S.O.S.! Longitud 145 30', latitud 29 , 15””, apareció en El Hogar (22 de enero de 1937), y la segunda, "Prohibido ser adivino en este barco", en Mundo Argentino (27 de septiembre de 1939) (Saítta, 2000: 306 y 316). Para terminar con la producción arltiana, faltan por mencionar dos obras perdidas: una primera novela de la que informan Mirta Arlt y Borré (1984: 31), Diario de un morfinómano, publicada en 1920 o 1921 en La novela cordobesa, y el manuscrito de una tragedia sobre Elena de Troya en la que Arlt estaba trabajando en el momento de su muerte (Mirta Arlt, 2000: 24). Además, en algunos estudios se cita otra pieza, La cabeza separada del cuerpo (Mavridis, 2006: [En línea]) o del tronco (Ogás, 2011: 37), atribuida a Arlt y así estrenada en mayo de 1964 en el Teatro del Pueblo. Finalmente se demostró que había sido elaborada por Barletta, utilizando fragmentos descartados de Escenas de un grotesco (Ogás, 2011: 37). Solo Mavridis (2006: [En línea]) hace referencia a otra novela anunciada por las mismas fechas que El pájaro de fuego, pero tampoco escrita: El emboscado rojo. 
y Salzman (2000), que el gusto militar de la época por los gestos grandilocuentes y los decorados ampulosos - tras el golpe de estado del general Uriburu el 6 de septiembre de 1930, Argentina vivía en una dictadura; mientras, el fascismo y el nazismo ganaban fuerza en Europa - condujo al autor, fiel observador del presente a través de sus aguafuertes, a elegir el teatro como forma de expresión idónea para reflejar la realidad del momento.

En todo caso, la mayoría de los críticos coincide en relacionar novela y teatro, considerando algunos de ellos que en las primeras obras ya se pueden detectar algunos rasgos dramáticos. Esa llamada teatralidad de la narrativa de Arlt es lo que vamos a revisar a continuación.

\section{La teatralidad en la obra de Arlt}

En los textos previos a 1932 encontramos ciertas conexiones con el teatro. Como detalle, de la multitud de referencias a la literatura que aparecen en las novelas de Arlt, algunas corresponden al género dramático: así, en El juguete rabioso, Silvio describe la vida de los Irzubeta como "más jocosa que un sainete bufo" (Arlt, 1981a: 16) y, en la saga de Los siete locos, Haffner se queja de que los saineteros pinten a los proxenetas como él como monstruos o animales exóticos (145), mientras el Astrólogo intenta ganarse la amistad de Hipólita comparando su conversación con la sincronía de un coro de tragedia griega (313). Pero más significativos resultan los cruces entre El amor brujo y Prueba de amor. Quizás la similitud de las tramas - las dos obras giran en torno a conflictos surgidos en relaciones convencionales de pareja: la necesidad de la virginidad en la mujer y la incerteza del amor- y la introducción de dos diálogos teatrales en la novela ${ }^{19}$ se deban al trabajo simultáne $0^{20}$ y a la experimentación propia de los primeros intentos de creación dramática. En las aguafuertes, Arlt ya había practicado, incluso un poco antes, esos diálogos de formato teatral: "El pan dulce del cesante" (El Mundo, 25 de diciembre de 1929), "El vecino que se muere" (5 de junio de 1930), "Dos millones de pesos" (15 de junio de 1930), "Acomodando a los correligionarios" (25 de junio de 1930) o "Diálogo de lechería" (9 de julio de 1931) son algunos ejemplos ${ }^{21}$.

Otra conexión más abarcadora entre las novelas y el teatro - al menos hasta Africa- es la similitud del carácter y el conflicto principal de muchos personajes. La crítica coincide en señalar que Silvio, Erdosain, Balder, Sofía, Saverio, Pedro, don Manuel y los demás empleados comparten la angustia, la soledad y la frustración ante la realidad miserable en la que viven; todos escapan de ella a través de la imaginación, fantaseando con historias de grandeza que acaban por destruirles.

Recapitulando, todo parece remitirnos a esa relación, aunque en muchos casos no vayamos más allá del terreno de la interpretación. Algunos analistas han utilizado el origen narrativo de la práctica teatral de Arlt, la sensación de continuidad entre un género y otro que da la semejanza de los personajes, e incluso el tópico -que vuelve el asunto más interesante- de que, a pesar de su carrera como dramaturgo, Arlt nunca "consiguió quitarse de encima el rótulo del novelista" (Mavridis, 2006: [En línea]), para proponer que esa teatralidad - la semilla del género dramático, el anuncio de la vocación teatral- ya existía en sus novelas. Así, Ogás (2011: 33) considera que el texto de "El humillado" "poseía tal teatralidad" que se escenificó "sin modificaciones sustanciales" y Gatti (2008) ve rasgos teatrales anticipados en la estructura de los diálogos ${ }^{22}$, en los mutis finales de El juguete rabioso y Los siete locos, y en el nulo desarrollo de los personajes ${ }^{23}$.

${ }^{19}$ Ambas escenas (Arlt, 1981a: 613-614 y 627-633) son imaginadas por Balder, que recrea para sí el espacio, los personajes y los diálogos (como hará Pedro en El fabricante de fantasmas). Estos elementos aparecen siguiendo los códigos de composición teatral: el escenario y la situación se presentan a través de acotaciones y las intervenciones, que contienen indicaciones sobre la actitud con la que deben ser dichas, se introducen tras el nombre de los personajes.

${ }^{20}$ El amor brujo ya fue anunciado en noviembre de 1931 (con fecha de publicación y todo) en el prólogo de Los lanzallamas (ver Arlt, 1981a: 310 ), y Mirta Arlt (2000: 20) afirma que el autor le entregó a Barletta el texto de Prueba de amor por esas mismas fechas.

${ }^{21}$ Las fechas de publicación proceden de Saítta (2000).

22 "Los personajes [de las novelas y los cuentos] dialogan entre sí utilizando ritmos dramatúrgicos, como si estuvieran en escena, y utilizan respuestas rápidas y frases cortas, de gran potencia visual más que narrativa" (Gatti, 2008: 75).

${ }^{23}$ Inversamente, otros autores ven procedimientos narrativos en la base de la construcción dramática. Por ejemplo, Woodyard (2000: 147) opina que "como resultado de sus experiencias anteriores en la narrativa, [Arlt] conocía bien la técnica de escribir diálogos, que podía utilizar con eficacia en sus piezas teatrales". Por otro lado, Mirta Arlt comparte la idea de la continuidad y los cruces entre un género y otro, que aprecia tanto en la tensión dramática de los soliloquios, los diálogos y los conflictos de las novelas (1990), como en la función de narrador que Sofía, Saverio/Susana, Pedro, Cipriano y Baba asumen, en distinto grado, al crear con su imaginación o sus relatos el marco para el desarrollo de la acción (2000). 
Esta última cuestión merece un comentario aparte. Según Gatti (2008: 74-75),

el cambio de Arlt hacia la dramaturgia ya se percibe latente en las características de los personajes de sus novelas: sus protagonistas no se transforman a lo largo de la obra, ni cambian su vida, sino que permanecen idénticos a sí mismos. [...] Sin darse cuenta, Arlt va desarrollando un proceso interior en el que expresa la necesidad de transformar al lector en espectador. [...] A lo largo de toda la producción novelesca arltiana, resulta evidente la disposición teatral de los personajes: el lector de sus novelas a menudo se ve obligado a imaginar visualmente las escenas que el escritor no describe (por la carencia de didascalias) y se detiene a contemplar la vida terminada de un personaje que nunca cambia. Es como si Arlt estuviera pintando naturalezas muertas y sintiera la necesidad de trasladarlas al escenario.

Estas ideas, que se repiten en otros artículos como el de Salzman (2000) o el de Mavridis (2011), proceden de un uso descontextualizado de ciertos fragmentos del libro de Óscar Massota (1965), Sexo y traición en Roberto Arlt. Si leemos completa la nota en la que el autor habla del carácter poco novelístico de los personajes de Arlt - "verdaderos "caracteres", en el sentido clásico del término, destinos petrificados, naturalezas muertas" (20) - , vemos que se refiere a que su vida parece ya hecha y los lectores solo asistimos a escenas puntuales de la misma, teniendo que imaginar los momentos que las unen y la forman entera ${ }^{24}$, no a que por permanecer estáticos (y faltar las acotaciones) resultan más teatrales — si es que los personajes teatrales no se desarrollan- Capdevila (1993: 56) ya había prestado atención y matizado esa nota: "que no haya evolución en la vida de los personajes no quiere decir que sus historias no se realicen en una cierta temporalidad" y, con su análisis de un pasaje de Los lanzallamas - ese en el que Erdosain empieza a pensar en diseñar una fábrica de gas fosgeno y proclama para sí que ama la vida y sonríe solo, en la oscuridad de su cuarto- le da otro sentido a la teatralidad en la narrativa de Arlt: "no es exagerado afirmar", dice, "que su vida [la de Erdosain] se encuentra gobernada por "una necesidad de drama". Lo teatral lo seduce por su eficacia, por su "prestigio"“ (55).

El teatro, en el sentido amplio del término - el de 'actuar', 'fingir' - y no como género literario con unos rasgos propios, está presente en las novelas de Arlt porque la simulación (todas las formas de engaño, de farsa, los complots, los espectáculos, las poses, las historias copiadas o inventadas para sobrevivir) forma parte de lo que cuenta en ellas y de cómo lo hace. En ese sentido, los personajes de sus piezas dramáticas también son teatrales: ellos también mienten compulsivamente, viven en fantasías espectaculares, organizan bromas monumentales y disfrutan hablando con grandes palabras ${ }^{25}$. Esta teatralidad es una constante en toda la obra de ficción del argentino, independientemente del género. De ahí también, en parte, esa sensación de continuidad y reciprocidad.

¿Cómo se manifiesta esto en los textos? Por un lado, en la práctica de la mentira y el engaño, y, por otro, en la expresión grandilocuente de los personajes, característica de la farsa. Desde El juguete rabioso hasta El desierto entra en la ciudad, todos los personajes de Arlt se encuentran, en algún momento, interpretando un papel, representando una comedia ${ }^{26}$ que a veces, víctimas de la desgracia o la locura, terminan por creerse: Silvio, creyendo que ha conseguido quemar la librería de don Gaetano, se imagina interpretando ante un juez el papel de la conciencia arrepentida; Erdosain trepa a un árbol y se convence de que la locura ha triunfado en él; el Astrólogo contrata a dos tipos para que se hagan pasar por un mayor y un buscador de oro, y monta el falso asesinato de Barsut; los Espila se disfrazan de mendigos para timar a la gente; Balder finge ser un hombre honesto, un caballero ante su futura suegra; Guinter organiza toda una puesta en escena - que incluye dinero falso y fuego- para probar el amor de Frida; los personajes de humo se ven obligados a actuar como piden los soñadores en sus fantasías; el Rentista monta un número en la oficina de Rosma;

${ }^{24}$ La impresión de que solo asistimos a determinadas escenas de la vida de los protagonistas (que además parecen permanecer "idénticos a sí mismos") tiene que ver con el tipo de novela que Arlt practicó, especialmente en Los siete locos, Los lanzallamas y El amor brujo: en vez de desplegar una trama narrativa tradicional, estas obras muestran la historia de una psicología, desarrollando minuciosamente los pensamientos y estados de los personajes ante una serie de acontecimientos, a veces mínimos. Que el conflicto principal sea psicológico quizás hace estas novelas menos novelescas, pero no las convierte directamente en teatrales.

${ }^{25}$ Paradójicamente, esta teatralidad podría tener relación con las tramas y el estilo de cierta literatura de bandoleros y piratas, especialmente con los folletines de las aventuras de Rocambole, escritos por Ponson du Terrail entre 1857 y 1870, y de los que Arlt era un lector entusiasta. El bandido aparece como ideal de Silvio en El juguete rabioso y como personaje en Trescientos millones, pero, más allá de la referencia explícita, hay en estas novelas por entregas un gusto por las conspiraciones y los golpes de efecto, y un tono grandilocuente que podrían recordar, en algunos momentos, a los personajes de Arlt.

${ }^{26}$ Hacer la comedia es una expresión muy repetida en los textos de Arlt. Con ese mismo sentido de 'mentira' o 'montaje' también encontramos novela (véase el diálogo entre Erdosain y el Buscador de Oro en Los siete locos: Arlt, 1981a: 231-236) o cuento (véase la escena VI del acto I de La fiesta del hierro). 
Saverio interpreta a un coronel en la despiadada broma de Susana, que hace a su vez de reina desterrada; Pedro asesina a su mujer y se declara inocente; Axuxa y Salem, vestido de mujer, tienden una trampa a Mahomet para que Hussein cumpla su venganza; don Carlitos organiza unos festejos espectaculares — con túnicas para los invitados, cantos rituales y una gran estatua ardiente de Baal Moloc- para celebrar el aniversario de la fábrica de cañones del Sr. Armstrong, mientras el Presbítero finge ante el Fotógrafo no reconocer a Mariana - que lleva toda la vida ocultando que es analfabeta- en unas imágenes comprometidas para poder chantajearla él solo...

A esta predisposición de los protagonistas hacia la interpretación se suma, muchas veces, un deseo de grandeza, fama y atención, que se refleja en su actitud sarcástica, cínica, altiva, espectacular y grandilocuente. Así, en numerosas ocasiones, el lenguaje que utilizan los personajes resulta "engolado y literario, [...] altisonante y declamatorio" (Golluscio, 2000: 142), como ocurre, por ejemplo, en la burla de Saverio el cruel, cuyos participantes - incluido, finalmente, Saverio- cambian su registro familiar porteño por un castellano más afectado, como de comedia antigua ${ }^{27}$; o en los discursos poéticos de don Manuel y el Mulato en $L a$ isla desierta ${ }^{28}$. Además, las descripciones y las acotaciones marcan, con frecuencia, gestos excesivos que preceden a intervenciones teatrales en el sentido que estamos manejando ${ }^{29}$. Estas, a veces, son comentadas como tales por los propios personajes, poniéndose de relieve la falsedad y lo artificial de lo que está sucediendo en escena: cuando Guinter le dice a Frida que pretende quemar todo el dinero que posee, esta le grita “¿Estás loco?” y él le responde "Dejá las exclamaciones para las heroínas del teatro poético" (Arlt, 1981b: 386).

Esa es, precisamente, la sensación que busca producir la farsa ${ }^{30}$, que, junto con la burlería ${ }^{31}$ (bastante similar, más frecuente en piezas breves), fue el género más practicado por Arlt en su teatro ${ }^{32}$, la manera que eligió para mostrar ciertas deficiencias del mundo: que la mentira funciona como un potente motor de la sociedad -en Los siete locos y Los lanzallamas ya había quedado claro que "los hombres se sacuden solo con mentiras" (Arlt, 1981a: 232), y en Saverio el cruel llegamos a ver hasta qué punto eso se cumple-; lo vacío y falso de las convenciones burguesas asociadas al amor, que vuelven imposible su certeza - esto queda patente en los juegos de seducción entre amantes que aparecen en El amor brujo, Prueba de amor, Trescientos millones, El fabricante de fantasmas y La fiesta del hierro-; o la duda que siempre surge cuando representación y locura coindicen -en La juerga de los polichinelas y Escenas de un grotesco sabemos que la locura es real, y, aunque en Saverio el cruel lo descubrimos al final, el daño está hecho y el malestar permanece, mientras que en El desierto entra en la ciudad no se resuelve: nunca averiguamos si César es un demente, un farsante o un nuevo y auténtico mesías-. En definitiva, la teatralidad es una forma de expresar lo endeble que resulta a veces la realidad.

${ }^{27}$ Como ejemplo, uno de los monólogos de Susana: “Árboles barbudos... y silencio. (Inclinándose hacia el suelo y examinándolo.) Ninguna huella de ser humano. (Con voz vibrante y levantando las manos al cielo.) ¡Oh, Dioses! ¿Por qué habéis abandonado a esta tierna doncella? ¡Oh! Sombras infernales, ¿por qué me perseguís? ¡Destino pavoroso! ¿A qué pruebas pretendes someter a una tímida jovencita? ¿Cuándo te apiadarás de mí? Vago, perdida en el infierno verde, semejante a la protagonista de una tragedia antigua. Pernocto indefensa en panoramas hostiles..." (Arlt, 1981b: 449-450).

${ }^{28}$ Véanse el parlamento de don Manuel que comienza con "No sé. La vida no se siente. Uno es como una lombriz solitaria en un intestino de cemento. [...]" (Arlt, 1981b: 554) y el de Cipriano que le sigue.

${ }^{29}$ Así se presenta a la madre de Irene en El amor brujo: "La señora se detuvo a dos pasos del joven con gesto de primera actriz [...] [y] lanzó un horrible: - Caballero, ¿a qué debo el honor de su visita?" (Arlt, 1981a: 530-531); y la misma indicación aparece en Trescientos millones cuando Sofía decide seguirle el juego de la comedia amorosa al Galán: “(Haciendo gestos de primera actriz.) ¿Cómo..., tú me eres infiel?” (Arlt, 1981b: 415). Otros ejemplos, en La fiesta del hierro: "Julio. —La madrastra engaña a papá. AMBRosio (enfático). - No. (Con falsa compunción.) ¡Pobre señor! ¿Cómo averiguó eso, niño?” (636); y en El desierto entra en la ciudad: “EsciPIóN (melodramático). — ¡Qué destino! ¡Traicionar al amigo desventurado!" (693).

${ }^{30}$ DETLI [En línea]: farsa. Pieza breve, de carácter cómico y grotesco cuyo argumento se basa, por lo común, en la confrontación de personajes populares, algunos de los cuales intentan -y consiguen, de acuerdo a la condición carnavalesca de dicha forma dramática- burlarse o dominar a los otros. Disponible en: http://www.proyectos.cchs.csic.es/detli/sites/default/files/Farsa.pdf [última consulta 02/02/21].

${ }^{31}$ DLE [En línea]: burlería. 1.engaño. 2. cuento fabuloso o conseja de viejas. 3. ilusión (\| concepto o imagen sin verdadera realidad). 4. irrisión, mengua. Disponible en: https://dle.rae.es/burler\%C3\%ADa?m=form [última consulta 02/02/21].

${ }^{32}$ Escenas de un grotesco, La fiesta del hierro y El desierto entra en la ciudad llevan el subtítulo de farsas; y La juerga de los polichinelas, Un hombre sensible y La isla desierta, el de burlerías. El resto de obras se clasifican así: Trescientos millones, pieza en un prólogo y tres actos; Saverio el cruel, comedia dramática en tres actos; El fabricante de fantasmas, drama en tres actos divididos en seis cuadros; Separación feroz, diálogo dramático; y África, drama en cinco actos y un exordio al uso oriental (Arlt, 1981b). 


\section{Narrativa y tradición teatral, dramaturgia y teatro independiente}

Sin embargo, también se puede hablar de teatro en la narrativa de Arlt desde otra perspectiva: si nos referimos, no a las características del género dramático, sino a su tradición, aunque ello suponga, paradójicamente, establecer una distancia entre novelas y piezas teatrales; porque, a pesar de la continuidad y los cruces que hemos comentado, ambas fueron el resultado de proyectos distintos.

El teatro de Arlt se desarrolló fuertemente ligado a los comienzos de la escena independiente argentina. En torno a los años treinta, en la capital porteña empezaron a crearse una serie de espacios e iniciativas alternativos $^{33}$ a los circuitos comerciales, en los que, o se hacía negocio del teatro por horas con sainetes, revistas y zarzuelas, espectáculos breves, animados, costumbristas y accesibles a un gran público, o se representaba a los autores nacionales más consolidados, como Florencio Sánchez o Armando Discépolo. Cansados del "pomposo teatro de variedades" (Arlt, 1981b: 127) y del sistema teatral de las compañías, con sus primeras figuras y sus directrices de interpretación, la generación de nuevos dramaturgos buscó separarse de esa tradición y crear algo más experimental y trascendente, a la par que crítico con ciertos aspectos de la realidad y puesto al servicio de la premisa de una cultura digna para el pueblo.

De ese movimiento de renovación nació el Teatro del Pueblo, que se convirtió en el centro de la escena independiente. Para Arlt, fue un espacio de creación y representación (ya hemos mencionado que, salvo $E l$ fabricante de fantasmas, todas sus obras - las que se representaron en la época- se estrenaron allí), y, aunque no compuso sus piezas según el proyecto ideológico-estético de Barletta, el realismo crítico (Pellettieri, 2000), sí que se avino plenamente a la idea de hacer algo distinto, que acabó siendo diferente incluso de lo alternativo. De ahí que la crítica de la época - poco acostumbrada a ver fantasmas o sucesos tremendos en el escenario- apenas valorara la innovación que supuso su teatro y lo considerara marginal dentro de su producción (Díaz y Sikora, 2000), condicionando la recepción y el estudio posteriores de su dramaturgia.

No obstante, las piezas de Arlt no permanecen del todo ajenas a la tradición dramática argentina; lo que ocurre es que el autor eligió distintos elementos de la misma para cada género. Por ejemplo, en El juguete rabioso se reconoce el mundo de inmigración, miseria y frustración del grotesco criollo. Astier no es un recién llegado con abuelos e hijos a su cargo, ni habla el italocriollo característico de los protagonistas discepolianos (es, por el contrario, hijo de inmigrantes y, por tanto, está más integrado en la sociedad porteña; habla, además, la jerga propia de los adolescentes de barrio pobre fascinados por la delincuencia ${ }^{34}$ ), pero, como a ellos, el funcionamiento de la sociedad le impide desarrollar su verdadera vocación, pues la vida se le va en los trabajos precarios que debe aceptar para mantenerse. Toda la novela está llena de inmigrantes en la misma situación: el zapatero andaluz que le descubre a Silvio los folletines de bandoleros, los Irzubeta, los Naidath, don Gaetano, doña María y "Dío Fetente"... Y tanto en la saga de Los siete locos como en los cuentos de El jorobadito encontramos el mismo ambiente de penurias y fracasos, aunque no tan ligado a la inmigración. Sofía y Saverio también podrían sumarse al grupo ${ }^{35}$, pero, en general, los personajes del teatro de Arlt pertenecen a otros mundos (como el de la oficina o el oriental) y a otras clases sociales (adineradas, como los jóvenes de Saverio el cruel, la familia de César en El desierto entra en la ciudad o los empresarios de La fiesta del hierro) apenas explorados en la novela. De alguna manera, sus piezas —al formar parte de ese proyecto de renovación teatral- rompieron con el costumbrismo al que el público de la época estaba habituado, separándose así, también, de sus novelas y aguafuertes, que habían recogido esa tradición saineteril de conventillos y tipos locales.

$\mathrm{Si}$ en El juguete rabioso encontramos algunos ejemplos de lenguaje marcado por la procedencia del personaje $^{36}$, estos no llegan en ningún caso a la fusión de italiano y español de Discépolo, y sirven como seña

\footnotetext{
${ }^{33}$ Como el Teatro Libre (1927), el Teatro Experimental de Arte (1928) o el laboratorio teatral El Tábano (1929) (Fernández, 2008: 866).

${ }^{34}$ El discurso de Silvio, Enrique y Lucio es una mezcla de lunfardo - ¡Mirá si te "cachan”! Nos arrean a todos a la "leonera"“ (Arlt, 1981a: 36)giros coloquiales, como el "vesre" — ¿La prensa?... y claro... me pongo los pantalones viejos, no se me rompa el "jetra”“ (22), y una forma de hablar resabida, sacada de los libros y películas que conocen: "El aprendizaje de ratero tiene esa ventaja: darle sangre fría a uno, que es lo más necesario para el oficio. Además, la práctica del peligro contribuye a formarnos hábitos de prudencia" (22).

${ }^{35}$ Sobre todo Sofía, y más si tenemos en cuenta el origen de Trescientos millones, que Arlt explica en el prólogo de la obra: el suicidio real de una joven sirvienta española que él mismo cubrió cuando trabajaba como reportero policial para el diario Crítica en 1927. En cuanto a Saverio, en la pieza no hay ninguna referencia a su posible condición de inmigrante y su lenguaje no muestra ninguna marca que no sea de la variedad porteña; sin embargo, Golluscio (2000: 140) propone que, al compartir el nombre y ciertos rasgos de carácter con el protagonista de El organito (1925) de Discépolo, la memoria del público lo consideró de manera natural un personaje "de la misma estirpe dramática y literaria".

${ }^{36}$ Como el del zapatero andaluz — "Ezte chaval, hijo... iqué chaval... era ma lindo que una rroza y lo mataron lo miguelete...” (Arlt, 1981a: 11)—, doña María —.Yo te levanté... ¿Quién era tu madre... sino una "bagazza" que andaba con todos los hombres? [...] Sí, ¿quién te sacó del hambre y te vistió...? Yo, "strunsso"“" (49)— o la señora Rebeca Naidath —"Qué vida, frau, qué vida” (64)—.
} 
de identidad, no como símbolo de la incomprensión y la distancia entre generaciones. En cambio, a pesar de que en el teatro de Arlt ese tipo de marcas lingüísticas desaparecen ${ }^{37}$, el autor no deja de utilizar distintos lenguajes en escena -en este caso, tonos o registros más realistas, normales o prosaicos frente a otros más teatrales, grandilocuentes o serios- para dar cuenta de lo teatral de las situaciones, dentro de las propias piezas $^{38}$, o crear contrastes humorísticos y rebajar la tensión dramática de las historias ${ }^{39}$.

\section{El otro giro}

Quedan por comentar dos cuestiones que quizás sirvan para considerar este asunto del paso al teatro desde otra perspectiva: la primera tiene que ver con el conflicto que los personajes de Arlt sostienen con la ficción y cómo, de alguna forma, su expresión podría estar relacionada con la elección del género dramático; y la segunda, con un último giro de la producción arltiana, que esta vez no se manifestó exactamente en el cambio de un género a otro sino en la preferencia y el desarrollo de las tramas frente a los caracteres.

Los personajes de las novelas de Arlt tienen complejas y distintas relaciones con la ficción: o actúan como los protagonistas de los libros que han leído, o anhelan para sus desordenadas vidas las formas perfectas y la grandeza que ofrecen las historias de novelas y películas, pero todos sueñan, crean fantasías a su medida para escapar de la realidad, existiendo al límite en ambos mundos. Lo mismo les sucede, en esencia, a Sofía, Saverio, Pedro y los oficinistas de La isla desierta. Arlt parece dibujar un camino a través de estas obras, una ida confiada hacia la ficción y una vuelta fatal a la realidad. Puede que el autor viera en el género dramático — que, más que ningún otro, es capaz de poner en juego los límites entre invención y realidad, locura y cordura - una posibilidad de darle más potencia y profundidad a ese conflicto.

Por otro lado, más o menos a partir de 1938, parece haber otro giro en la obra de Arlt, que se vuelve más narrativa, en el sentido tradicional del término: el del puro contar historias, desde un principio a un final, progresivamente, con unos personajes-tipos, familiares al imaginario colectivo. En África, La fiesta del hierro, El criador de gorilas o Viaje terrible, Arlt cambia los detallados y circulares despliegues psicológicos de sus novelas por las aventuras, los espías, las venganzas o, simplemente, tramas más cerradas y construidas. Menos estudiadas por considerarse extrañas o menores en el conjunto de su producción, en estas obras finales desaparecen la alternancia y la mezcla de planos habitual, decantándose directamente o por la fantasía o por la realidad.

Normalmente se presta menos atención a los últimos años de Arlt, como si conocer hasta los más mínimos detalles de 1932 nos fuera a dar la clave del asunto y el resto dejara de contar, cuando en África -en un momento en el que el autor ya estaba consolidado como dramaturgo- puede observarse, de nuevo, un claro trasvase entre géneros: no solo porque su trama proceda de tres cuentos anteriores (o más o menos simultáneos a la composición de la pieza ${ }^{40}$, sino porque la obra en sí misma está llena de narraciones, pues, aunque el jefe de conversación ${ }^{41}$ establece el marco de la acción ${ }^{42}$, son los propios personajes los que, al relatar los sucesos de sus vidas, entretejen la historia final ${ }^{43}$. Además, el desenlace no podría ser más de cuento de hadas: tras cumplir su venganza, la pierna de Hussein se endereza milagrosamente y todos son felices.

\footnotetext{
${ }^{37}$ Excepto en el Jardinero de La fiesta del hierro, pero se trata de un personaje secundario.

${ }^{38}$ Por ejemplo, en la farsa de Susana o en las escenas amorosas de Trescientos millones (escena III, cuadro II, acto I), El fabricante de fantasmas (escena VI, cuadro I, acto I) o La fiesta del hierro (escena I, acto I).

${ }^{39}$ Como en el primer encuentro de Sofía y Rocambole (escena III, cuadro I, acto I), en el diálogo de Saverio y Simona en la pensión (escena II, acto II) o en algunos momentos de la discusión final de Susana y Saverio (escena VIII, acto III).

40 "La aventura de Baba en Dimisch esh Sham", "Rahutia la bailarina" y "Hussein el Cojo y Axuxa la Hermosa", que aparecieron en El Hogar a lo largo de 1937 - el 23 de enero, el 20 de mayo y el 25 de junio, respectivamente (Saítta, 2000)—. Posteriormente fueron recogidos en la colección de El criador de gorilas.

${ }^{41}$ La figura del xej-el-clam había cautivado a Arlt en su viaje por el norte de África. A este tipo de narradores tradicionales que recitaban e interpretaban historias ante un público les dedica su aguafuerte "El narrador de cuentos. Abuso de ingenios y piadosos. Precursores del teatro", El Mundo, 3 de agosto de 1935 (Saítta, 2000).

42 "Voy a narrar la sangrienta historia de Hussein el Cojo y Axuxa la Hermosa, que ocurre en Dimisch esh Sham. Y también la historia de Rahutia la Bailarina, de El Mockri y de su hermano. Y la suerte que corrió Mahomet el Platero. [...] El misterio de una doble venganza. El destino cumplido. [...] Haced un círculo en torno de Baba. Poned el trasero sobre las piedras. [...] (Bate el tambor.) Comenzaré, comenzaré... que comienzo..." (exordio al uso oriental; Arlt, 1981b: 560).

${ }^{43}$ Aunque Baba se ve envuelto en los acontecimientos que llevan a la muerte de El Mockri, no se entera del desenlace hasta que un Mercader lo anuncia en el zoco (final del acto II), y el Hermano de El Mockri solo conocerá la verdad de lo ocurrido cuando Rahutia, para salvar su vida, se lo cuente (final del acto IV). En cuando al nexo de las dos tramas principales, este se descubre cuando Hussein le relata a Axuxa la historia de su cojera (acto III).
} 
Quizás tener en cuenta este cambio de última hora en la manera de hacer literatura de Arlt sirva para ampliar el panorama y dejar de ver el paso al teatro como el solo y absoluto giro de su trayectoria. Toda la obra de este autor es una gran lección sobre las posibilidades de interpretación de ciertos términos literarios, su rigidez a la par que su amplitud, y las diferencias entre la tradición y los recursos de composición de los géneros.

Sin embargo, a pesar de todo lo apuntado, es imposible conocer con exactitud las razones que llevaron a Roberto Arlt al teatro. Además, su muerte temprana, a los cuarenta y dos años, corta toda posibilidad de esbozar una trayectoria real de lo que habría sido su obra completa. Arlt no se fue acercando lentamente a la plenitud o la madurez que se les augura a los autores, ni pudo reflexionar sobre el conjunto de su producción y el lugar de cada etapa. Quizás hubiera seguido escribiendo teatro y sus novelas se considerarían hoy como algo anecdótico, ligado a sus inicios de escritor; o quizás su negocio de medias irrompibles, en el que trabajó con tanto empeño desde 1941, hubiera triunfado y la literatura sería, entonces, lo anecdótico de su vida. Todo lo que podamos decir es una lectura posterior, el camino lo dibujamos nosotros.

\section{Referencias bibliográficas}

Arlt, Mirta (1990), "Roberto Arlt: un creador creado por el Teatro Independiente". Buenos Aires. Disponible en: $\underline{\text { http://www.teatrodelpueblo.org.ar/dramaturgia/arlt001.htm }}$

----, ----- (2000), "La locura de la realidad en la ficción de Arlt", en Osvaldo Pellettieri (ed.). Roberto Arlt: dramaturgia y teatro independiente (Cuaderno del GETEA nº. 12). Buenos Aires: Galerna, págs. 13-24.

Arlt, Mirta y Omar Borré (1984). Para leer a Roberto Arlt. Buenos Aires: Torres Agüero.

Arlt, Roberto (1981a). Obra completa. Tomo 1. Buenos Aires: Carlos Lohlé.

----, ------- (1981b). Obra completa. Tomo 2. Buenos Aires: Carlos Lohlé.

Capdevila, Analía (1993), "Sobre la teatralidad en la narrativa de Arlt", Cuadernos Hispanoamericanos. Los Complementarios, $\mathrm{n}^{\circ} .11$, julio, págs. 53-57.

Castagnino, Raúl H. (1964). El teatro de Roberto Arlt. La Plata: Universidad Nacional de La Plata/Facultad de Humanidades y Ciencias de la Educación.

Díaz, Silvina y Marina Sikora (2000), "Nota sobre la recepción de la obra dramática de Roberto Arlt en su tiempo", en Osvaldo Pellettieri (ed.). Roberto Arlt: dramaturgia y teatro independiente (Cuaderno del GETEA nº. 12). Buenos Aires: Galerna, págs. 155-165.

Fernández, Teodosio (2008), "El teatro hispanoamericano del siglo XX”, en Trinidad Barrera (coord.). Historia de la literatura hispanoamericana. Tomo III. Siglo XX. Madrid: Cátedra, págs. 855-899.

Gatti, Giuseppe (2008), "El teatro de Roberto Arlt y Luigi Pirandello: la sonrisa que viene de lo amargo", Cartaphilus. Revista de Investigación y Crítica Estética, 3, págs. 72-85.

Gnutzmann, Rita (2004). Roberto Arlt: innovación y compromiso. La obra narrativa y periodística. Lleida: Universitat de Lleida/Asociación Española de Estudios Literarios Hispanoamericanos.

Golluscio, Eva (2000), "Los personajes-memoria: dos Saverios para un organito”, en Osvaldo Pellettieri (ed.). Roberto Arlt: dramaturgia y teatro independiente (Cuaderno del GETEA no . 12). Buenos Aires: Galerna, págs. 137-145.

Goloboff, Gerardo Mario (1989). Genio y figura de Roberto Arlt. Buenos Aires: Eudeba.

Massota, Óscar (965). Sexo y traición en Roberto Arlt. Buenos Aires: Jorge Álvarez.

Mavridis, Spyridon /2006), "Roberto Arlt: fundador del teatro independiente", Espéculo. Revista de estudios literarios, año XI, n'. 33. Disponible en: http://webs.ucm.es/info/especulo/numero33/teatarlt.html

Ogás, Grisby (2011), "Pilares de la escena independiente argentina. Roberto Arlt en el Teatro del Pueblo", Stichomythia, $\mathrm{n}^{\circ}$. 11-12, págs. 28-41.

Pellettieri, Osvaldo (2000), "El Teatro del Pueblo y sus puestas de los textos de Roberto Arlt", en Osvaldo Pellettieri (ed.). Roberto Arlt: dramaturgia y teatro independiente (Cuaderno del GETEA nº. 12). Buenos Aires: Galerna, págs. 43-55.

Saítta, Sylvia (2000). El escritor en el bosque de ladrillos. Una biografia de Roberto Arlt. Buenos Aires: Sudamericana.

Salzman, Isidro (2000), "Una lectura de la obra dramática de Roberto Arlt en el contexto de la década del 30", en Osvaldo Pellettieri (ed.). Roberto Arlt: dramaturgia y teatro independiente (Cuaderno del GETEA nº 12). Buenos Aires: Galerna, págs. 69-83.

Sanz, María de los Ángeles (2000), “Bibliografía de Roberto Arlt. Textos dramáticos”, en Osvaldo Pellettieri (ed.). Roberto Arlt: dramaturgia y teatro independiente (Cuaderno del GETEA n ${ }^{\circ}$. 12). Buenos Aires: Galerna, págs. 167188.

Verzero, Lorena (2006), “Actividades y estrenos (I)”, en Osvaldo Pellettieri (dir.). Teatro del Pueblo: Una utopía concretada. Buenos Aires: Galerna, págs. 11-43.

Woodyard, George (2000), "La textualidad dramática de Roberto Arlt: catarsis y sorpresas", en Osvaldo Pellettieri (ed.). Roberto Arlt: dramaturgia y teatro independiente (Cuaderno del GETEA nº. 12). Buenos Aires: Galerna, págs. 147-154. 